\title{
La otra montaña
}

Ronald Obando Brenes

\section{El adiós}

Enterrados quedaron los restos de aquel sabio Apu que conocí unos treinta años atrás. Con una franca sonrisa me saludaba invitándome a cualquier menester del momento. Y sin que yo lo previera, de su mundo no pude más que anclar esta última recompensa que en divagantes sueños o en abstractas realidades me contó durante la última entrevista.

Recuerdo el camino al cementerio, malogrado por los incesantes aguaceros de la recién pasada invernal temporada. Entre tenues calores y frescos vientos se acercaba el febrero presurosamente. Pero después de esa tarde ya nada fue igual.

Entre hombros valientes y apesadumbrados cargaban el féretro de los saberes; el último Apu se había ido.

Los sollozos no se hicieron esperar cuando por última vez se exhibió el cadáver en el cementerio ante aquella inusual multitud que aguardó ahí en basto silencio. Aun los niños más pequeños recibían un ingrato recuerdo de luto que nunca más podrían olvidar. En este momento creo que nació la leyenda.

Por mi parte, no pude obviar imponer mi brazo dentro de aquella fosa para enderezar su corona hacia el poniente, hacia donde debía viajar.

\section{Contemplaciones}

Entre matices de movimiento se internaban sus conceptos, su método era simple y práctico, en un permanente estado de sincronía entre lo físico y lo espiritual. Permanentemente sopesaba su discurso sobre el respeto y la custodia a la Pachamama, las razones sin violencia para lograr la paz, que con ello se podría escalar a estados de serenidad y armonía en donde se potencia el desarrollo interior y el espíritu del hombre. Dicho en otras palabras, el desarrollo de una existencia con vitalidad y plenitud.

Resultaba muy ameno el solo hecho de visitarlo, admirar su ambiente de meditación y relajación, muy diferente al mundo exterior de donde provengo, el que solo creemos percibir, según decía aquel. Su cultivo filosófico, además, le permitía asentarse sobre una dimensión con una intención hallada. Admitía que algunas abstracciones podrían derivarse de la llamada transformación cuántica. Sobre este particular afirmaba que, por medio de la consciencia, todos creamos nuestra realidad particular.

Decía que la vida es primordialmente abundancia, que no se puede "tener" abundancia, porque ya "somos" abundancia, por lo tanto es imposible perder lo que nos 
viene dado al nacer en este planeta Tierra. Lo que nos aleja de la relación con la abundancia es simplemente un bloqueo interno basado en falsas ilusiones sobre nosotros mismos o sobre la concepción que adoptamos de la vida. Mediante la Transformación Cuántica se pueden esculpir eficaces herramientas de labranza que permiten cambiar, mutar y hasta crear la existencia de una forma distinta para resolver de manera fácil y versátil lo que nos bloquea, logrando con ello, un estado anhelado de paz, consciencia y bienestar.

Hablaba de que la Sabiduría perenne siempre ha estado ahí, solo quien desaprenda y se logre desempoderar del concepto típico de dominación terrestre podrá abrirse a un entendimiento de la historia aún desconocida, aún invisibilizada; aquella que comprende el papel del espíritu y el alma, o los temas no dados como la astrología, las razas humanas, la nueva economía y política, la educación, el sistema solar cósmico, que la vida y la muerte serían al fin comprensibles. Pero, aun este plano dimensional es todavía difícil de alcanzar para un meditador facelista-hacedor. Le dolía que el mundo hubiera perdido la capacidad de meditar. Su acción conlleva algunos pasos como la concentración y el enfoque, pero además conlleva una conciencia subconsciente, subrayaba.

En el grado en que se valore y se desarrolle la gestión de un estado cognitivo que apropie cada elemento de este planeta como un ser vivo y más como una parte elemental de la conciencia y viceversa, se podría entonces llegar a comprender nuestra relación y la de cada ser con el planeta.
Por tanto, nada en la vida es fortuito, más allá de la causalidad y las estadísticas, más allá del tiempo y el espacio que conocemos, la sincronía de las No causas también está; si los fenómenos externos están, estos son transmitidos de algún modo imperceptible hacia la psique, pero además puede crearse una vía inversa y la psique puede afectar el orden natural de las cosas. Con esto quería decir que cualquier estado interno puede derivar en uno externo.

Al final, lo que nos ocurre, bueno o malo, está ahí para que aprendamos algo acerca de nosotros mismos. Mientras sigamos creyendo que nuestra propia vida no depende de nosotros, podremos seguir eludiendo cualquier tipo de responsabilidad. Y mientras sigamos pensando que todo esto no es más que un accidente, podremos seguir marginando cualquier posibilidad de encontrar la respuesta a la pregunta existencial ¿para qué vivimos?

Si contemplamos cada situación como un problema, se adopta el papel de víctima $\mathrm{y}$, por tanto, sentirnos impotentes; pero si enfrentamos los desafíos como retos de oportunidad, la sensación de bienestar, alivio y comprensión será fácil de obtener por naturaleza.

\section{Reacomodo}

Ahora que repasaba las enseñanzas de este antiguo Apu, lograba entender algo de su filosofía y los hechos que talvez estos generarían en mi realidad. Las circunstancias encajaban una con otra y me ponía a pensar sobre las consecuencias de la psique. ¿Acaso la transmutación cósmica que originó este Apu con su muerte, solo era una 
esencia vedada a un plano dimensional distinto? ¿Podría este sabio haber enfocado su propia muerte para trascender a otro estado natural?

Cada vez que me preguntaba esas cosas difíciles, se partía mi comprensión y solo podía aumentar mi fascinación en el hecho de lo que esta experiencia logró cambiar en mí: la comprensión de un mundo inserto en él conscientemente.

Ya por entonces algunos de los Principios Originarios venidos de una cosmología solidaria se empezaban a manifestar en la Pachamama.

La caída de las potencias del orden capitalista encontró al fin su racionalidad en decadentes problemas sin solución dimensional. Los pocos que se salvaron de la catástrofe del hambre tuvieron que convertirse a los antiguos saberes de armonía trascendental y dejar atrás en su totalidad cualquier vínculo consumista y explotador, aunque ya sus genes estaban condenados a la extinción debido a la contaminación radioactivo-transgénica a que fueron sometidos. Nunca más esta gente viviría en la Tierra.

Sin embargo, la Alianza del Sur salió fortalecida; desde su fisonomía integracionista no se vio afectada por el caos abrazador, debido a que el dominio de estos sobre las causas mismas y las predicciones oraculares de los chamanes hechas con las Piedras de Ica, al fin sirvieron para contener cualquier intento de agresión e involucramiento.

Eran aquellas piedras la herencia de un pasado remoto, de una civilización que pobló la Tierra y que no concuerda con las explicaciones de la historia oficial, pero que gracias a la comprensión de la historia desconocida se habían podido encontrar explicaciones aún incipientes pero factibles para sobrevivir a la catástrofe.

Otra casualidad o coincidencia eran aquellos oráculos localizados en tierras latinoamericanas. Parece como si debían estar siempre ahí y llegar a cumplir en firme para algún propósito histórico como recién ocurría. Una sintonía fina, talvez. Y aún quedan muchas más por desenterrar en el desierto de Ocucaje; solo imagino cuántas más razones podrían despejarse desde esas areniscas y graníticas figuras. Mas solo en el debido contexto se podrían entender, decían los sabios, no antes. Solo se daría en su debido tiempo y en su espacio correcto. Eso había que respetarlo.

\section{Desinformaciones}

Antes de la muerte del Apu de la montaña, durante una entrevista este me contó de una fascinante travesía. Conforme la humanidad destructora avanzaba, las fuerzas de atracción cósmicas se desencadenaban y se contraían en el espacio. Desde que parcialmente y erróneamente se publicaron algunas especulaciones sobre el fin del mundo al malinterpretar los códices mayas para final del año 2012, fueron los mismos países de dominio capitalista quienes apropiándose de una información no destinada para ellos por su incubo modelo de desarrollo, desencadenaron de una manera adrede una serie de eventos catastróficos que degeneró en su propia destrucción.

No aprendieron del pasado, iparece! La Atlántida de Platón o los gigantes de Rapanui. 
En fin, la incidencia de su errática vibración en torno a una información indescifrable para entonces había logrado atraer hacia ellos cataclismos de orden natural y luego atracciones de origen artificial. Fue la insistencia en manipular el clima mediante un proyecto llamado HAARP cuyo fin bélico servía para generar estratégicas crisis mundiales, lo que terminó desviando sus efectos devastadores sobre la misma falla de San Francisco, desembocando una magna erupción volcánica del Monte Santa Elena y rematando con la formación de dos gigantes huracanes que incluso alcanzaron las costas de Nueva York debido a la calidez oceánica provocada. Con esto, la costa oeste quedó en ruinas. Al mismo tiempo, E.E.U.U. trató de culpar a Rusia y a China sobre el uso indebido de sus armas climáticas sobre ellos, llegando a escalar tensiones e incitando a una guerra neorrealista en el año 2015, en donde además se explotaron armas químicas y biológicas, tan desconocidas y encubiertas como lo es la misma cura del cáncer o el sida en los laboratorios corporativos de la exigua nación imperialista.

El falso control del clima, así como el desconocimiento sobre el caos en sus dimensiones físicas y psíquicas, les generó una catarsis anunciada desde su entropía sistémica. En esta guerra no se declararon perdedores ni ganadores, ya que todos los que participaron recibieron nefastos daños que los obligaron a sobrepasar cualquier costo y capacidad. Muchos terminaron suicidándose ante la desesperanza nunca antes imaginada desde que el orden capitalista entró en crisis financiera en 2006.

Quienes no participaron de la guerra, se ampararon en sus conocimientos ancestrales para sobrevivir marginalmente al conflicto; y desde aquel momento exacto se derivó un estado de consciencia endógeno y originario en el SUR. Para finales del año 2012, el Secreto Inka los tenía mejor protegidos que cualquier escudo antimisiles.

\section{EI secreto}

Los Apus (espíritus de los cerros) fueron los depositarios ancestrales de la sabiduría Inka. Recordemos que las fuerzas invisibles de la sincronía poseen una explicación física, de ahí que la psique interactúe con esta en una forma natural y no escape de estas fuerzas.

Los inkas conocían el campo geomagnético de la Tierra y por ello sabían de la especial condición geomagnética del Qosqo al que llamaron "Ombligo del mundo", el cual construyeron con forma de puma: así el puma en la cosmovisión andina es un tótem que representa al Kay pacha o "el espacio tiempo de aquí", o sea, el mundo presente donde viven los humanos y la naturaleza, que se interconecta con el Hanan Pacha o "mundo de arriba" y el Ukhu pacha o "mundo interior", así como el Hawapacha, el 4to cosmos, que no cuarto puede verse, "que está más allá de las estrellas"

El tawapacha (los cuatro cosmos) sería la expresión del pariverso (llamado actualmente universo) que es el todo girado en paridad. Dicha paridad conforma el $\mathrm{Pa}-$ chakama (padre del tiempo y el espacio) en el plano "WA" o plano metafísico inmaterial, invisible al ojo humano, y el pachamama (madre del tiempo y el espacio) en su plano físico "KA" como la expresión de lo material, y ciertamente dichos 
principios giran en paridad, en un eterno tiempo cíclico llamado "pachakutin" que está representado como un amaru (serpiente cósmica) que se muerde la cola.

Según la cosmovisión andina, hay lugares en la cordillera donde el plano metafísico "WA" y el plano físico "KA" confluyen por medio del illa tiqsi o "luz fundamental, o rayo primigenio"; a esos lugares les llaman "WA-KA" (huaca) y en esos mismos lugares las grandes culturas andinas construyeron los templos, las pirámides y las wakas sagradas desde tiempos inmemoriales, pues eran lugares sagrados que catalizaban energía y permitían conectarse a los otros mundos de la pacha (cosmos)...

La leyenda hablaba de que el primer Inka Manco Capac usó una varilla de oro para hallar el Cusco (capital del Tawaintisuyu). Esa varilla se llamaba Tupayauri, que traducido del quechua significa "aguja inteligente", que funcionalmente fue usada como un catalizador de energía electromagnética. Esto fue así porque en el Cusco confluye el centro de la energía magnética de la Tierra.

A sabiendas de que el ecuador magnético se mueve 8,2 kilómetros al año, actualmente se encuentra a 19 kilómetros al sur del observatorio magnético de Wankayo (2012); por tanto, ha estado moviéndose de norte a sur, desde Cajamarca (1802) a Trujillo (1823), Ancash (1838), Pasco (1910) y retornó a Qosqo en 1955. Ha estado así viajando hacia el sur hasta el año 2012, pero en julio de 2013 inicia su retorno hacia la dirección norte ¿por qué motivos?. Aún no sabemos, pero la línea ecuatorial va de norte a sur y luego retorna de sur a norte, mas esto explicaría por qué los inkas y otras culturas conocían el pachakuti del orden y pachakuti del caos (tiempos de retorno).

\section{Vestigios}

Amanecía lentamente, las cinco menos cuarto. El día después del desastre. Ya todo el pachakuti acabó.

Manchados salieron aquellos capitalistas, era fácil notar sus síntomas. La mirada perdida y su incesante movimiento de piernas a causa de su tremenda ansiedad y especulativa mentalidad. El trauma hizo su efecto, conforme bajaban los niveles de adrenalina. Pocas horas de vida más prolongarían su agonía. No me quedé ahí a verlos morir; no por desidia ni indiferencia, sino porque ya era imposible hacer algo más.

Muchas advertencias se habían anunciado, pero nadie las creyó. Los otrora imperialistas del mundo habían desaparecido para siempre. Exiguos caminos que llevaron a la oscuridad. Una oscuridad gris púrpura que envolvía la atmósfera decantando con el viento en su helada desazón.

De aquello nadie podía hablar más; lo que quedó, -simplemente quedó allí- para que la Naturaleza lo reconstituyera, lo absorbiera con los siglos en nuevos dibujos de esperanza en la lentitud de los tiempos terrestres.

\section{Manifiesto}

1.1 La filosofía galáctica había llegado, finalmente, a nuestro mundo; talvez siempre había estado aquí, y tan solo 
nos resistíamos a observarla y practicarla. Llegó en una doctrina que abrió los cielos a los mundos que pasan pruebas de vida; las galaxias y sus mundos que no pidieron ser probados en una vida, ven el Macrocosmo tal y como era este mundo, donde las galaxias son unitarias y comunistas por Principio Solar; sublime doctrina en que el todo sobre el todo pertenece a todos; un estado ideal de seres que unen filosofías iguales para causas iguales; un mundo en su pedido de vida, que no captó desde el principio la grandeza de esta doctrina; la única que une a la inocencia y no la divide. Quien no compartió en común sus propios intereses, le fue impedida toda salvación del colapso.

1.2 Si los que gobernaban insistieron en mantener un orden de división, iban contra las leyes del todo sobre el todo. Esta insistencia sería la causa de la tragedia de esta humanidad, porque mientras estos demonios gobernaban, transcurrían los segundos vividos en una división espiritual.

1.3 Las vidas en los planetas son relativas al interés y al adelanto intelectual de los seres. Cuando se pide nacer de nuevo, se pide para adelantar; para aprender; y esto es cierto, sólo cuando se cumple la Ley Solar. La ley es luz de conocimiento, y su cualidad y calidad son universales. A nosotros nos tocaba impregnar de magnetismo invisible todo lo que el universo creó así como este principio en nosotros y desde lo microscópico.
1.4 En el cosmos se lucha por el dominio de filosofías; porque así es la imperfección. Para llegar a un punto, existen infinitos caminos; el libre albedrío los escoge; y cada idea es una microscópica parte de su propio cielo. La ley del libre albedrío es una ley que está expuesta para escoger frecuencias mentales, de diferentes cualidades y calidades, en todos los instantes del pensar; y mientras se piensa, se genera magnetismo que satura la geometría exterior del cuerpo; porque el cuerpo queda impregnado de todos los hechos provocados por la idea. El cuerpo, por tanto, transmite y recibe esas frecuencias alrededor del mismo cuerpo humano. En el aura coexisten 318 colores que armonizan un equilibrio mental total, supeditado por la rotación y traslación del planeta. Cuando ocurren transformaciones en el planeta, como son los terremotos y maremotos, ¿acaso se pierde ese control mental?

Así es, porque el magnetismo del cuerpo hace un "todo" con los elementos de la naturaleza. De nuestras células y poros salen infinitos cordones que nos unen a las moléculas de los elementos. He aquí, con esto, una de las causas de la adoración hacia lo material; la fe materializada; la fe de los espíritus poco evolucionados; la fe intuitiva y no ilustrada; una fe hermanada con la adoración material; la fe enseñada por la roca religiosa; la fe que divide a los hijos del Padre; la fe que divide al rebaño; la fe que causará un llorar y crujir de dientes; porque su cualidad y calidad no concuerdan, ni encajan con las leyes cósmicas. 


\section{El Gran Viaje}

Bienvenidos a la Máquina del Tiempo. El tiempo se abre, se cierra, se extiende, se dilata. ¿Adónde iremos hoy? Ordenen nada más.

Si los órdenes son construcciones temporales en un estado atemporal macro desconocido como el dado "verdadero orden o nuevo orden de cosas"; entonces cuando no exista la linealidad del tiempo, el sustento de la ilusión perderá su aparente solidez dentro de un orden. Paradójico, difícil, irracional, talvez, en mentes poco desarrolladas.

\section{Abrochar los cinturones ...}

La humanidad parece ser arrastrada por el tiempo a un ritmo donde no se ejerce ningún control, y que conduce a la destrucción. Lo grave es que la idea de felicidad y seguridad como ilusión llega a sobrepesarse en el condicionamiento del tiempo. Entonces, ¿la rencarnación pareciera ser una solución para tener más tiempo? Sin embargo, en cada vida, la rueda del karma sigue girando, y más aún, cada elemento del mundo futuro se pierde, se deteriora, se desequilibra imposibilitando cada vez más esa tan ansiada vida. Entonces, ¿destruimos desde ahora nuestra vida futura?

\section{Iniciando cuenta regresiva...}

$Y$ es que todo es debido a los estragos que causa el tiempo. El tiempo envejece, siente hambre, sed, se comunica, se enferma, duele..., de lo contrario se podría pasar mucho tiempo totalmente inconscientes de cómo pasa en el tiempo.

\section{Iniciando trasmutación...}

Esta es la experiencia de vivir en el "ahora"-; no en el TIEMPO que aún no llega. Ese es el momento eterno inmutable de la conciencia pura, -sin cuidados o preocupación-. Sin embargo, mientras se siga creyendo en la ilusión y se continúe reconstruyéndola a cada momento, se encontrarán restringidos por los límites que el cuerpo físico parece imponernos; a medida que el tiempo pasa, ustedes aparentemente envejecen y se desmoronan hasta convertirse en nada.

\section{Estado actual: TRANSMUTADO}

$\mathrm{Al}$ desprenderse naturalmente del cuerpo físico, hasta ese momento se entrará en razón de que el tiempo y la ilusión se han ido; pero habrán permanecido completos, perfectos, intactos y delirantemente felices!

\section{Encuentro}

Cuando cerré la reja del cementerio, mi mirada pudo apreciar aquellos últimos rayos de luz ocultándose sobre la otra montaña. Fue hasta ese instante que comprendí por completo hacia dónde debía viajar. Gracias, Apu, por hacerme entender, en mí estará su conocimiento infinito, el que siempre ha estado, el que siempre estuvo en todos. Hasta la vista, Señor de las Montañas.

Hoy el Sol se oculta tras la montaña; mas mañana aparecerá en la otra.

-FIN 


\section{Bibliografía}

\section{EL GRAN VIAJE}

Smallman, John (Canalizador): "La ilusión está perdiendo su atractivo para ustedes".

En fecha 09/16/2009, Blog "Un Palacio en el Sol" Sitio Web: Tomado de http:// lightworkers.org/channeling/88034/ illusion-losing-its-appeal-you

Traducido por Marcelo Jiménez, en sitio web: http://evoluciondelespiritu.blogspot. com/

\section{CONTEMPLACIONES}

La Transformación cuántica: En sitio web http://www.transformacion-cuantica.es/ transformacion-cuantica-origen.html

\section{EL SECRETO}

El Secreto Inka: En sitio web: https:// www.facebook.com/groups/yachachiq/

Tradición andina: edad de oro escrito por Chávez Campos Chávez C., Teodosio Chávez C., Israel Chávez S. y Nadia Chávez S., Chávez Sumarrivar Chávez S.

Pachakuteq, aproximación a la cosmovisión andina, Federico García, Pilar Roca, 2004, Editorial lumbreras

La Raíz Sagrada WA y los ciclos cósmicos en la cosmovisión andina quechw, Pachakuteq Ninanturmanya, Revista Serpiente emplumada. Rimaq marka, Año 5519 de la era del V Sol de la Xma Luna

Jym Qhapaq Amaru. YACHACHIQ - Investigación y estudios inkásicos.

\section{MANIFIESTO}

Soto Romero, Luis Antonio: Autor de "Los Rollos del Cordero de Dios": Movimiento Alfa y Omega. Lima Perú. En sitio web: http://www.alfayomega.com.pe/ principal.htm

Brazo en Costa Rica: Programa en Radio Actual L-V 10pm. 